\title{
Tradução comentada do artigo de Guillaume de 1896 sobre a temperatura do espaço ${ }^{+*}$
}

\author{
A. K. T. Assis \\ Instituto de Física ‘Gleb Wataghin' - UNICAMP \\ Campinas - SP \\ M. C. D. Neves \\ Departamento de Física - FUEM \\ Maringá - PR
}

\section{Resumo}

Apresentamos uma tradução completa para o português, comentada, do artigo de Charles Édouard Guillaume (1861-1928), de 1896, sobre a temperatura do espaço interestelar. O trabalho aqui traduzido é importante por ser a estimativa mais antiga que conhecemos da temperatura adquirida por um corpo que esteja no espaço interestelar distante das outras estrelas. Esta temperatura seria devido a um estado de equilíbrio no qual a radiação recebida por este corpo das estrelas ao seu redor seria igual à radiação emitida por este corpo. Esta estimativa é anterior ao nascimento de George Gamow (1904-1968) que é considerado em muitos textos didáticos, erroneamente, como tendo sido a primeira pessoa a prever esta temperatura.

Palavras-chave: Temperatura do espaço.

\footnotetext{
${ }^{+}$Commented Portuguese translation of Guillaume's paper of 1896 about the temperature of space

* Recebido: abril de 2014.

Aceito: maio de 2014.
} 


\begin{abstract}
We present a complete Portuguese translation of the 1896 paper by Charles Édouard Guillaume (1861-1928) about the temperature of interstellar space. The importance of this work is that it is the oldest estimate known to us of the temperature acquired by a body which is in interstellar space far away from other stars. This temperature would be due to an equilibrium state in which the radiation received by this body from the stars around it would be equal to the radiation emitted by this body. This estimative happened prior to the birth of George Gamow (1904-1968) who is considered erroneously in many textbooks as being the first person to have predicted this temperature.
\end{abstract}

Keywords: Temperature of space.

\title{
I. Introdução
}

Apresentamos uma tradução completa para o português, comentada, do artigo de Charles Édouard Guillaume (1861-1938), de 1896, sobre a temperatura do espaço interestelar, (GUILLAUME, 1896). As Notas de Rodapé do artigo são dos tradutores.

Guillaume foi um físico suíço que recebeu em 1920 o prêmio Nobel de física "pela melhora na precisão de medições na física e pela descoberta de anomalias em ligas de aço-níquel." Seu avô teve uma fábrica de relógios em Londres. Seu pai foi um relojoeiro, que além de construir relógios de precisão, estudava os instrumentos de medição de tempo. Guillaume interessou-se desde cedo por cronômetros marinhos. Estudou na Escola Politécnica de Zurique, onde obteve seu doutoramento. Em 1883 foi contratado como assistente do Escritório Internacional de Pesos e Medidas, em Sèvres, França, tornando-se seu diretor de 1915 até sua aposentadoria em 1936. Foi Presidente da Sociedade Francesa de Física além de membro de inúmeras outras Academias e Sociedades Científicas na Europa. Casou-se em 1888 e teve três filhos.

Descobriu ligas de aço-níquel que denominou invar e elinvar. O invar tem um coeficiente de dilatação térmica quase nulo, tornando seu uso de interesse prático na construção de instrumentos de precisão nos quais seja relevante que suas dimensões permaneçam constantes com a variação de temperatura do ambiente, como no caso de termostatos e pêndulos de relógios astronômicos. Já o elinvar tem 
um módulo de elasticidade que não muda com a variação de temperatura do ambiente. Ele é útil na construção de instrumentos elásticos cujas propriedades não devem variar com a temperatura do ambiente, como é o caso do cronômetro marinho. Estes estudos eram muito importantes à época devido à importância da determinação precisa da longitude em navios que cruzavam o mundo. Prêmios dedicados à determinação da longitude foram oferecidos por diversos Estados europeus desde o século XVII (SOBEL, 2008).

Sobre termometria, Guillaume escreveu em 1886 o trabalho "Études thermométriques" (Estudos sobre termometria) e, em 1889, o livro "Traité de Thermométrie" (Tratado de Termometria).

O trabalho aqui traduzido é importante por ser a estimativa mais antiga que conhecemos da temperatura adquirida por um corpo que esteja no espaço interestelar distante das outras estrelas, (ASSIS; NEVES, 1995a; ASSIS; NEVES, 1995b; ASSIS; NEVES, 2013a; ASSIS; NEVES, 2013b; ASSIS; NEVES, 2013c). Esta temperatura seria devido a um estado de equilíbrio no qual a radiação recebida por este corpo das estrelas ao seu redor seria igual à radiação emitida por este corpo. Esta estimativa é anterior ao nascimento de George Gamow (1904-1968) que é considerado em muitos textos didáticos como tendo sido a primeira pessoa a prever esta temperatura. A estimativa de Guillaume é também relevante pelo fato de utilizar a lei de Stefan (1835-1893), de 1879, que caracteriza um estado de equilíbrio térmico do corpo com a radiação ao seu redor. De acordo com a lei de Stefan, a taxa de emissão de energia de um corpo por meio da radiação térmica a partir de sua superfície é proporcional à quarta potência de sua temperatura superficial absoluta. Vamos representar por $P$ à potência irradiada pelo corpo em watts, $\sigma=5,669 \times 10^{-8} \mathrm{Wm}^{-2} \mathrm{~K}^{-4}$ à chamada constante de Stefan-Boltzmann, $A$ a área da superfície do corpo em metros quadrados, $e$ sendo uma constante chamada de emissividade do corpo (igual à fração da radiação incidente que é absorvida pela superfície), e $T$ à temperatura da superfície do corpo em kelvins. Neste caso a lei pode ser representada matematicamente por:

$$
P=\sigma A e T^{4}
$$

As referências à este trabalho de Guillaume foram utilizadas para o documentário Universe: The Cosmology Quest, produzido pelo cineasta e compositor Randall Meyers, quando a cronologia das previsões da temperatura da radiação cósmica de fundo são encadeadas historicamente em uma das passagens do filme, (MEYERS, 2004). 


\section{Tradução Comentada do Artigo de Guillaume sobre a Temperatura do Espaço}

\section{A Temperatura do Espaço}

Quando tentamos calcular a elevação da temperatura produzida em um ponto do espaço pela radiação das estrelas, encontramos uma grande dificuldade ao estimar a energia que elas emitem. Pela ausência de algo melhor, admitiremos inicialmente que a repartição da energia nos espectros das estrelas é a mesma que ocorre no Sol, e que sua energia radiativa está, como a do Sol, na mesma proporção que a intensidade luminosa ou fotográfica dos diversos astros.

Temos à nossa disposição diversos procedimentos para estimar a energia enviada pelas estrelas; sendo que um deles consiste em determinar a radiação de uma estrela da primeira magnitude, para em seguida deduzir a radiação do conjunto dos astros ao aplicar a fórmula de Gould ${ }^{1}$ para a enumeração das estrelas de cada magnitude. Mas este procedimento ainda é de difícil aplicação, já que a energia da radiação das estrelas mais belas está justamente no limite das grandezas mensuráveis com os instrumentos mais sensíveis. Além disso, a fórmula de Gould foi estabelecida para um certo número de grandezas das estrelas e, no caso que nos interessa, somos forçados a extrapolar, o que não ocorre sem perigo. Adotaremos aqui um procedimento mais simples, aquele que deriva da estimativa direta das ações fotográficas totais das estrelas e do Sol. O capitão Abney ${ }^{2}$ determinou recentemen-

Guillaume refere-se aqui a Benjamin Apthorp Gould (1824-1896), astrônomo norteamericano. Foi um dos iniciadores da astronomia observacional na Argentina, sendo diretor do Observatório Astronômico de Córdoba entre 1871 e 1885. O Observatório de Córdoba na Argentina foi muito importante para a história da astronomia latino-americana, especialmente porque essa Instituição forneceu telescópios e instrumentos para o então jovem físico alemão Erwin Finlay-Freundlich tentar registrar na Rússia os deslocamentos das posições das estrelas durante um eclipse solar total. O Observatório de Córdoba já havia tentado registrar, em 1912, estes deslocamentos em um outro eclipse solar total na América Latina, mas sem sucesso devido ao tempo nublado. A expedição de Freundlich ocorreu durante o ano que marcou a história da Rússia e de toda a humanidade, a revolução de 1914. Freundlich teve seus instrumentos confiscados e foi preso com outros cientistas acusados de espionagem (SANTOS; ARETTA, 1992).

Gould foi também o criador do periódico Astronomical Journal em 1849, o qual publicou até 1861. Foi um dos primeiros astrônomos a usar fotografia para estudar astronomia. Ele deduziu uma fórmula de acordo com a qual o número de estrelas aumenta em proporção à diminuição de seu brilho.

O nome completo do capitão Abney é William de Wiveleslie Abney (1843-1920), químico e astrônomo britânico. Trabalhou com os fundamentos químicos da fotografia colorida e 
te a razão da luz do céu estrelado para a luz da Lua cheia; encontrando esta razão igual a 1/44, levando em consideração todas as reduções devidas à obliquidade dos raios com relação à placa [fotográfica]; e devidas à absorção atmosférica. Ao dobrar este valor para os dois hemisférios, e ao adotar a razão da intensidade luminosa da Lua para aquela do Sol como sendo 1/600.000 (uma média grosseira das medidas de Wollaston ${ }^{3}$, de Bouguer ${ }^{4}$ e de Zöllner ${ }^{5}$ ), encontraremos que o Sol nos envia 15.200.000 vezes mais energia vibratória do que o conjunto das estrelas. A elevação da temperatura de um corpo isolado no espaço, e submetido apenas à ação das estrelas, será igual ao quociente da elevação da temperatura devida ao Sol sobre a órbita da Terra pela raiz quadrada de 15.200.000, ou seja, aproximadamente 60. Além disso, este número deve ser considerado um valor mínimo, já que as medidas do capitão Abney, feitas em South Kensington, podem ter sido distorcidas por alguma outra fonte de luz. Concluímos que apenas a radiação das estrelas manteria o corpo de prova que assumimos ter sido colocado em diferentes locais do céu à temperatura de 338/60 $=5,6$ [graus] absolutos $=-207,4^{\circ}$ centígrados.

Não se deve concluir que a radiação das estrelas eleve em 5 ou 6 graus a temperatura dos corpos celestes. Se o astro em questão já possui uma temperatura muito diferente do zero absoluto, sua perda de calor é muito mais forte; encontraremos a elevação da temperatura devida à radiação das estrelas ao calcular a perda

com fotometria astronômica. Recebeu a medalha Rumford em 1882. Foi um pioneiro ao fotografar o espectro infravermelho do Sol em 1887, pesquisando também a perda da luz solar na atmosfera terrestre.

${ }^{3}$ William Hyde Wollaston (1766-1828), químico, físico e astrônomo britânico. Em 1820 foi eleito presidente da Royal Society. Desenvolveu um método físico-químico para processar o minério de platina, descobrindo durante esta época os elementos paládio (1803) e ródio (1804). Desenvolveu diversos instrumentos ópticos. Fez observações em 1802 das linhas escuras do espectro solar que conduziram à descoberta dos elementos químicos do Sol.

Pierre Bouguer (1698-1758) foi um físico e astrônomo francês. Fez estudos sobre a perda de luz ao atravessar a atmosfera terrestre, publicando seus resultados em 1729. Fez algumas das primeiras medidas em fotometria, encontrando que a luz solar era 300 vezes mais intensa do que a da Lua.

Johan Karl Friedrich Zöllner (1834-1882), astrônomo e físico alemão. Trabalhou com fotometria, construindo um astrofotômetro (1861). Fez medidas da magnitude aparente do Sol. Publicou um trabalho sobre a natureza dos cometas. Tentou deduzir a gravitação como uma força eletromagnética residual. Trabalhou com a eletrodinâmica de Weber (ASSIS, 1992; ASSIS, 1994; ASSIS, 1995). 
usando a lei de Stefan ${ }^{6}$. Encontramos assim que, para a Terra, a elevação da temperatura devida à radiação das estrelas é inferior a um cem-milésimo de um grau. Ainda assim devemos considerar este número como um limite superior da ação que buscamos calcular .

Ainda temos de insistir sobre a incerteza bem grande sobre os números que acabamos de calcular. Trata-se apenas, no momento, de sua ordem de grandeza. Contudo, pensamos que eles são bem aproximados para estabelecer, nos casos fora de dúvida, as condições de habitabilidade de alguns planetas. Em todo caso, parece bem provável que as estrelas fixas não tenham qualquer papel nos fenômenos térmicos do sistema solar.

\section{Charles Édouard Guillaume}

\section{Referências}

ASSIS, A. K. T. Curso de Eletrodinâmica de Weber. (Setor de Publicações do Instituto de Física da Universidade Estadual de Campinas - UNICAMP, Campinas, 1992). Notas de Física IFGW Número 5. Disponível em: $<$ http://www.ifi.unicamp.br/ assis >.

ASSIS, A. K. T. Weber's Electrodynamics. Dordrecht: Kluwer Academic Publishers, 1994. ISBN: 0792331370.

ASSIS, A. K. T. Eletrodinâmica de Weber: Teoria, Aplicações e Exercícios. Campinas: Editora da UNICAMP, 1995. ISBN: 8526803581.

ASSIS, A. K. T.; NEVES, M. C. D. History of the 2.7 K temperature prior to Penzias and Wilson. Apeiron, 1995a. v. 2. p. 79-84.

\footnotetext{
${ }^{6}$ Joseph Stefan (1835-1893), físico e matemático austro-esloveno. Estudou na Universidade de Viena, sendo depois professor desta Universidade e Diretor do Instituto de Física a partir de 1866. Em 1879 apresentou a lei que ficou conhecida por seu nome segundo a qual a radiação total emitida por um corpo negro é proporcional à quarta potência de sua temperatura. Em 1884 esta lei foi estendida por Ludwig Boltzmann (1844-1906), um ex-estudante de Stefan. Desde então ela é conhecida como lei de Stefan-Boltzmann.

${ }^{7}$ Ou seja, a temperatura real de um corpo que fica apenas sob a influência da radiação das estrelas deve ser menor do que o limite superior obtido por Guillaume de 5,6 K.
} 
ASSIS, A. K. T.; NEVES, M. C. D. The redshift revisited. Astrophysics and Space Science, 1995b. v. 227. p. 13-24. Este artigo também foi publicado em Plasma Astrophysics and Cosmology, A. L. PERATT (Ed). Dordrecht: Kluwer Academic Publishers, 1995. p. 13-24. Disponível em:

$<$ http://www.ifi.unicamp.br/ assis >.

ASSIS, A. K. T.; NEVES, M. C. D. Geschichte der 2,7 K Temperatur vor Penzias und Wilson. Tradução (2013a) do inglês para o alemão por M. Pohl do seguinte artigo: ASSIS, A. K. T.; NEVES, M. C. D. History of the $2.7 \mathrm{~K}$ temperature prior to Penzias and Wilson. Apeiron, 1995. v. 2. p. 79-84. Tradução alemã disponível em: <http://www.ifi.unicamp.br/ assis $>$.

ASSIS, A. K. T.; NEVES, M. C. D. Die Rotverschiebung, neu bewertet. Tradução (2013b) do inglês para o alemão por M. POHL do seguinte artigo: ASSIS, A. K. T.; NEVES, M. C. D. The redshift revisited. Astrophysics and Space Science, 1995. v. 227. p. 13-24. Tradução alemã disponível em:

$<$ http://www.ifi.unicamp.br/ assis $>$.

ASSIS, A. K. T.; NEVES, M. C. D. O desvio para o vermelho revisitado. In: O. FREIRE JR., O.; CARNEIRO, S. (Eds.) Ciência, Filosofia e Política: Uma Homenagem a Fernando Bunchaft. Salvador: EDUFBA, 2013c. p. 53-69.

GUILLAUME, C. E. La temperature de l'espace. La Nature, v. 24, series 2, p. $210-211 ; 234,1896$.

MEYERS, R. Universe: The Cosmology Quest, 2004. Disponível em:

$<\mathrm{http}: / /$ www.youtube.com/watch?v=KmotCQCxQEI $>$,

$<$ http://www.youtube.com/watch?v=m-2uvQ_MJz8>,

$<$ http://www.randallmeyers.com/films.php $>$.

SANTOS, A. M. N.; ARETTA, C. Eddington e Einstein: Verificação Experimental da Teoria da Relatividade Generalizada na Ilha do Príncipe. Lisboa: Gradiva, 1992.

SOBEL, D. Longitude. São Paulo: Companhia das Letras, 2008. 